\title{
Processamento de tomate seco de diferentes cultivares
}

\author{
Dorivaldo da Silva RAUPP ${ }^{1}$, José Raulindo GARDINGO², Letícia dos Santos SCHEBESKI ${ }^{3}$, Camila Andrade \\ AMADEU $^{4}$, Aurélio Vinicius BORSATO5
}

\begin{abstract}
RESUMO
O tomate seco apresenta um consumo crescente, principalmente como ingrediente de pizzas e lasanhas, e na forma de aperitivo. A pesquisa avaliou o processo de produção de tomate seco de quatro cultivares comerciais (Italiano, Débora Plus, Santa Cruz, Delícia) e a qualidade dos produtos prontos. O tomate foi fatiado em quatro cortes longitudinais, sentido pedúnculo-ápice, e as fatias tiveram suas massas loculares removidas. $\mathrm{O}$ secador foi regulado nas primeiras três horas para $100^{\circ} \mathrm{C}$, seguido de $80^{\circ} \mathrm{C}$ até completar a secagem do produto, o qual apresentou uma umidade residual em torno de $60 \%$. A cv. Delícia produziu a maior perda de $39,8 \%$ durante o preparo das fatias frescas, sendo que as perdas para as demais cultivares variaram entre 32,7 a $34,3 \%$. Os rendimentos dos tomates inteiros em produtos prontos foram iguais a: cv. Débora Plus 9,1\%; cv. Santa Cruz 8,9\%; cv. Delícia 8,6\%; e cv. Italiano 8,3\%. O maior tempo de secagem de 9 horas e 25 minutos foi para a cv. Delícia; as demais apresentaram um mínimo de 8 horas e 10 minutos (Italiano) e um máximo de 8 horas e 35 minutos (Santa Cruz). Os tomates secos das cultivares Italiano e Débora Plus apresentaram-se levemente adocicados; o da cv. Santa Cruz foi ainda menos; e, esta característica foi de difícil percepção para o da cv. Delícia, que também teve uma mastigação não suave e mais prolongada. Apesar da diferença, os produtos tomates secos obtidos a partir dessas cultivares não diferiram significativamente quanto ao paladar quando degustados por provadores não treinados.
\end{abstract}

PALAVRAS-CHAVE: tomate seco, secagem, agroindústria, alimento funcional.

\section{Dried tomato processing of different cultivars}

\section{ABSTRACT}

Consumption of dried tomatoes has been increasing, mainly as an ingredient of pizzas and lasagnas, and also as an appetizer. This study evaluated the production process of four commercial varieties (Italiano, Débora Plus, Santa Cruz, Delícia) and the quality of the finished products, which had a moisture content of around $60 \%$. The tomatoes were sliced into four longitudinal cuts in the stalk-apex direction and the seed masses were removed. The drier was set at $100^{\circ} \mathrm{C}$ for the first three hours, followed by $80^{\circ} \mathrm{C}$ until the drying was complete. Delícia had the greatest moisture loss $(39.8 \%)$ during the preparation of the fresh slices, while the losses of the other cultivars varied between $32.7 \%$ and $34.3 \%$. The yields of whole tomatoes in terms of finished product were: Débora Plus 9.1\%; Santa Cruz 8.9\%; Delícia 8.6\%; and Italiano 8.3\%. The longest drying period of 9 hours and 25 minutes was noted for Delícia; the drying times of the other varieties ranged from 8 hours and 10 minutes (Italiano) to 8 hours and 35 minutes (Santa Cruz). The dried tomatoes of Italiano and Débora Plus had a lightly sweet flavor; Santa Cruz had a less sweet flavor, and this characteristic was difficult note in Delícia. The dried samples of the latter cultivar were also not as soft and took longer to chew. Although there were differences between these products, they did not differ significantly to the palate when tested by untrained tasters (180 total).

KEY WORDS: dried tomato, drying, agroindustry, functional food.

\footnotetext{
1 Universidade Estadual de Ponta Grossa.

2 Universidade Estadual de Ponta Grossa.

3 Universidade Estadual de Ponta Grossa.

${ }^{4}$ Universidade Estadual de Ponta Grossa

${ }^{5}$ Embrapa Pantanal.
} 


\section{INTRODUÇÃO}

O tomate (Lycopersicon esculentum Mill) é um produto agrícola que ocupa o segundo lugar entre as hortaliças no que se refere à área cultivada e o primeiro lugar em volume industrializado (Camargo Filho e Mazzei, 1996). O tomateiro é originário do Peru, Equador e Bolívia, tendo sido cultivado no México, de onde foi levado para a Europa. Em 1554, já havia sido introduzido na Itália uma cultivar com frutos amarelados, que recebeu a denominação pomodoro, i.é., maçã-de-ouro. No século XVIII, o tomate já era largamente consumido em vários países europeus. Atualmente, seu uso como alimento é universal e sua produção é estimada em 89,2 milhôes de toneladas, sendo 24,5 milhôes destinados ao processamento, gerando milhares de empregos diretos e indiretos nos principais países produtores, como, Estados Unidos, Itália, Grécia, Turquia, Brasil e Rússia (Silva e Giordano, 2000).

A secagem, por consistir na remoção de umidade contida no interior de um produto, além de diminuir sua massa total, reduz a sua atividade de água e resultando como vantagem o prolongamento da vida útil. Os defeitos mais comuns apresentados por produtos alimentícios submetidos ao processo de secagem são a dureza excessiva, a dificuldade de re-hidratação, o surgimento de rugosidade na superfície do produto que denigre a sua aparência, bem como a degradação da cor, aroma e sabor (Fellows, 1994). Segundo Alves e Silveira (2002), citando Bonazzi et al. (1996), do ponto de vista dos consumidores, a qualidade dos produtos desidratados, como o tomate seco, são avaliadas levando em conta principalmente os aspectos sensoriais, sendo a sua aparência o critério mais importante numa apreciação global do produto no momento de adquiri-lo.

Romero-Peña e Kieckbusch (2003) sugeriram para acelerar a operação da secagem de tomate, em experimentos conduzidos com a cv. Santa Clara, iniciá-la com ar à $100^{\circ} \mathrm{C}$ até que cerca de $50 \%$ do conteúdo de umidade inicial do produto fresco sejam evaporados, seguida de $60^{\circ} \mathrm{C}$ até o produto ficar pronto. E, segundo esses autores, tal procedimento não promove uma deterioração da cor vermelha natural do tomate com grau completo de maturação. Raupp et al. (2007) avaliando condiçôes de secagem para tomate da cv. Carmem consideraram a combinação de temperatura de $100^{\circ} \mathrm{C}$ por $3 \mathrm{~h}$ seguida de $80^{\circ} \mathrm{C}$ como o tratamento que resultou em produto tomate seco de melhor qualidade.

O teor de sólidos do tomate afeta diretamente o rendimento da produção de produtos dele derivados, sendo o teor de sólidos solúveis, medido como ${ }^{\circ} \mathrm{Brix}$, uma das principais características utilizadas para estimar o rendimento. O teor de sólidos solúveis no fruto, além de ser uma característica genética da cultivar, é influenciado pela adubação, temperatura e irrigação. Os valores médios de ${ }^{\circ}$ Brix na matéria-prima recebida pelas indústrias no Brasil têm sido bastante baixos $\left(4,5^{\circ} \mathrm{Brix}\right)$. Entretanto, existem cultivares que possuem maior potencial genético, as quais podem apresentar, em determinadas condiçōes, valores próximos de $6,0^{\circ} \mathrm{Brix}$ (Silva e Giordano, 2000).

Com relação ao $\mathrm{pH}$, valor inferior a 4,5 favorece a conservação tanto do fruto in natura como dos produtos dele derivados. Também, o pH é uma outra característica do fruto que interfere no sabor (Silva e Giordano, 2000).

A importância do tomate, também como alimento funcional é atribuída ao seu principal constituinte bioativo, o licopeno. $\mathrm{O}$ crescente interesse na atividade antioxidante do carotenóide licopeno se deve à alegação de que esse poderoso antioxidante combate os radicais livres, retarda o envelhecimento e pode proteger contra o câncer, inclusive o de próstata. O licopeno é um carotenóide que confere a cor vermelha ao tomate, e, quanto mais intensa for a cor vermelha mais rico em antioxidante ele será (Fett, 2000; Giovanucci et al., 1995; Sgarbieri e Pacheco, 1999; Tolonen, 1995). Tomates que apresentam uma boa coloração, caracterizada pela cor vermelha-intensa e uniforme externa e internamente, possuem teores de licopeno de 5 a $8 \mathrm{mg}$ por $100 \mathrm{~g}$ de polpa (Silva e Giordano, 2000).

A pesquisa teve por proposta avaliar, comparativamente, o processo de produção de tomate seco, apresentando umidade em torno de $60 \%$, a partir de matérias-primas de quatro cultivares comerciais (Italiano AF7123, Débora Plus, Santa Cruz AF6165, Delícia), e, tendo por fim: (i) a caracterização da matéria-prima; (ii) determinar as perdas durante o preparo de fatias frescas de tomate; (iii) determinar os tempos de secagem; (iv) determinar os rendimentos em produtos prontos, os tomates secos; (iv) avaliar o gosto dos tomates secos.

\section{MATERIAL E MÉTODOS}

As matérias-primas, tomates in natura de quatro cultivares (Italiano AF 7123, Débora Plus, Santa Cruz AF 6165, Delícia), foram obtidas de um produtor da região de Ponta Grossa, PR. Os tomates apresentaram estádio de maturação maduro, caracterizado pelo aparecimento superficial de cor vermelha, e, para a cv. Delícia, da coloração amarela/alaranjada.

A secagem foi conduzida em secador com circulação forçada de ar, usando quatro bandejas de superfície contínua de $90 \times 80 \mathrm{~cm}$ e um termostato digital acoplado ao sistema de aquecimento para estabilização automática da temperatura interna.

Quatro cultivares de tomate comercial foram usadas para a transformação de fatias de tomate fresco em fatias secas. Em cada procedimento de processamento foram usadas quatro porçôes de tomates de cultivares diferentes, uma repetição por cultivar, constituindo assim uma parcela, e foram processados 
aproximadamente $8,0 \mathrm{~kg}$ de tomates inteiros frescos (matériaprima). Portanto, durante a secagem quatro bandejas do secador receberam porções de fatias frescas de tomates, sendo uma bandeja por cultivar.

Uma amostra de cinco unidades de tomate (matériaprima) foi utilizada para determinar a massa e o volume dos tomates inteiros. Esses tomates, após pesagem, foram colocados em uma proveta de $2000 \mathrm{~mL}$ a qual teve seu volume completado com água proveniente de outra proveta de igual capacidade. $\mathrm{O}$ volume da amostra corresponde ao volume de água que sobrou na proveta. A massa específica foi obtida por cálculo, dividindo o valor da massa da amostra pelo valor de seu volume.

Os tomates dessa amostra foram, a seguir, fatiados em quatro partes, corte longitudinal no sentido pedúnculoápice, e suas fatias foram isentas das porções loculares. Estas fatias, após serem transformadas numa massa através de um triturador industrial, foram usadas para a determinação de $\mathrm{pH}$, sólidos solúveis e massa seca. $\mathrm{O} \mathrm{pH}$ foi determinado diretamente nessa massa usando um medidor de $\mathrm{pH}$, calibrado prèviamente com soluções padrão próprias. $\mathrm{O}$ teor de sólidos solúveis, em ${ }^{\circ}$ Brix, foi determinado usando um refratômetro manual. A massa seca foi determinada usando uma amostra de $10 \mathrm{~g}$ a qual permaneceu em estufa com temperatura regulada à $70^{\circ} \mathrm{C}$ até peso constante.

O processamento do tomate inteiro fresco (matéria-prima) para a obtenção do produto "tomate seco", o qual seguiu as etapas básicas aplicadas por Raupp et al. (2007), está resumido no Fluxograma a seguir:

Lavagem do tomate inteiro $\rightarrow$ Tratamento com hipoclorito de sódio $\rightarrow$ Enxágüe com água $\rightarrow$ Pesagem $\rightarrow$ Cortes em fatias $\rightarrow$ Remoção da porção locular $\rightarrow$ Pesagem $\rightarrow$ Secagem $\rightarrow$ Tomate seco em embalagem plástica $\rightarrow$ Refrigeração à $10^{\circ} \mathrm{C}$, 24 horas $\rightarrow$ Armazenamento em freezer $\left( \pm 18^{\circ} \mathrm{C}\right)$.

Os tomates inteiros, depois de lavados superficialmente com água potável, permaneceram imersos por 15 minutos em solução aquosa contendo $0,2 \mathrm{~mL} \mathrm{~L}^{-1}$ de agente sanitizante (hipoclorito de sódio), o qual apresentou concentração de cloro ativo entre $2 \%$ a $2,5 \% \mathrm{p} / \mathrm{p}$. Em seguida, foram lavados em água potável.

Usando uma faca de aço inoxidável, cada tomate foi cortado em quatro fatias, sendo os cortes longitudinais no sentido pedúnculo-ápice. Cada fatia teve sua massa locular removida com o auxílio de uma colher. As fatias de tomates de cada uma das quatro cultivares, isentas de suas massas loculares foram distribuídas em quatro bandejas dentro do secador. As bandejas foram forradas previamente com papel manteiga.

O secador permaneceu com todas as suas saídas de ar fechadas até que a temperatura do ar interno atingisse $80^{\circ} \mathrm{C}$ (registrada no termostato digital externo). Ao atingir essa temperatura, foram abertas as saídas de ar do secador para permitir a saída do ar úmido. O secador foi regulado nas primeiras $3 \mathrm{~h}$ para a temperatura de $100^{\circ} \mathrm{C}$, seguida de $80^{\circ} \mathrm{C}$ até completar a secagem do produto.

A abertura do secador para avaliar o produto ocorreu em intervalos de 30 minutos e iniciou depois de decorridos 1 hora e 30 minutos de secagem. As fatias de tomates foram retiradas do secador quando apresentaram umidade residual pré-definida para $60,0 \%, \mathrm{~m} / \mathrm{m}$. A retirada de produto pronto foi auxiliada, além do aspecto visual, pela determinação do peso médio estimado para as fatias secas. As fatias secas foram guardadas em sacos plásticos e, a seguir, mantidas sob refrigeração por cerca de 24 horas na temperatura de $10^{\circ} \mathrm{C}$ para estabilização da umidade residual, e, finalmente, armazenadas no freezer $\left( \pm 18^{\circ} \mathrm{C}\right)$.

Os produtos prontos (tomates secos) das quatro cultivares, os quais apresentaram umidades residuais $(\mathrm{m} / \mathrm{m})$ pré-definidas para $60 \%$, foram caracterizados visualmente de forma descritiva quanto ao aspecto (coloração, formato), em cinco repetiçóes. Também, foram avaliados quanto ao grau de satisfação, com relação ao gosto, que produziram em julgadores não treinados (total de 180). O julgador atribuiu uma pontuação ao gosto do produto usando a escala hedônica verbal apresentada na Figura 1, a qual foi sugerida por Anzaldúa-Morales (1994), tendo por limite mínimo da escala a descrição "desgostei muitíssimo", pontuação=1, e, por limite máximo a descrição "gostei muitíssimo", pontuação=9.

Indique o quanto gostou ou desgostou dos produtos apresentados, segundo a seguinte escala:

\begin{tabular}{|l|l|}
\hline 1 & Desgostei muitíssimo \\
2 & Desgostei muito \\
3 & Desgostei \\
4 & Desgostei ligeiramente \\
5 & Nem gostei e nem desgostei \\
6 & Gostei ligeiramente \\
7 & Gostei \\
8 & Gostei muito \\
9 & Gostei muitíssimo \\
\hline
\end{tabular}

Paladar de tomate seco - cultivares diferentes

\begin{tabular}{|l|l|l|l|}
\hline Amostra 1 & Amostra 2 & Amostra 3 & Amostra 4 \\
\hline & & & \\
\hline Comentários:
\end{tabular}

Figura 1 - Escala hedônica verbal de nove pontos usada na avaliação sensorial.

Foi determinado o rendimento em produto pronto (tomate seco); a perda de matéria-prima (tomate inteiro fresco) durante o preparo das fatias frescas de tomate; o tempo de secagem; e a proporção de produto pronto por período de secagem. O rendimento em produto tomate seco foi calculado 
em relação à massa de fatias frescas e de tomates inteiros. A perda do processamento, calculada também em porcentagem, considerou a massa descartada da matéria-prima (tomate inteiro fresco) durante o preparo de fatias frescas.

O delineamento experimental utilizado foi o inteiramente casualizado, com quatro tratamentos (cultivares) e seis repetições (processamentos). Os dados referentes ao tempo de secagem e às porções de produto pronto retiradas do secador por período de secagem foram monitorados e apresentados em caráter complementar àqueles obtidos para análise sensorial, de modo a facilitar a compreensão de eventuais influências dos tratamentos (cultivares) na pontuação atribuída pelos julgadores selecionados. Os dados obtidos a partir da análise sensorial foram avaliados por meio de ANOVA, sendo as médias comparadas pelo teste de Tuckey a $1 \%$.

\section{RESULTADOS E DISCUSSÃO}

A caracterização das matérias-primas (tomates inteiros frescos) das cultivares Italiano, Débora Plus, Santa Cruz e Delícia está apresentada na Tabela 1 . O tomate da cv. Delícia teve o maior tamanho expresso por volume $(208,8 \mathrm{~mL})$ e a maior massa $(207,1 \mathrm{~g})$. E, o tomate da cv. Italiano apresentou o menor tamanho, volume de $126,0 \mathrm{~mL}$, bem como a menor massa de 119,2g. Já, os tomates das cultivares Débora Plus e Santa Cruz apresentaram valores, tanto para o volume como para a massa, intermediários entre os da cv. Delícia e da cv. Italiano, e foram próximos entre si. E, quanto à relação massa/volume do tomate inteiro (densidade), a cv. Delícia apresentou o maior valor, igual a 0,992 , seguida pela cv. Santa Cruz com 0,966, sendo que as cultivares Italiano e Débora Plus apresentaram os menores valores para a densidade respectivamente igual a 0,946 e 0,940 , e foram muito próximos entre si.

As fatias frescas de tomate das cultivares Italiano - Débora Plus - Santa Cruz - Delícia apresentaram teores de sólidos solúveis e de $\mathrm{pH}$ que variaram de 2,9 a 3,5 oBrix e de 4,1 14,3 , respectivamente (Tabela 1 ). Fatias frescas de tomate apresentando um maior teor de sólidos solúveis são, em geral, mais adocicadas, no entanto, quanto mais ácidas forem, menos perceptível será seu gosto adocicado.

O produto tomate seco obtido a partir de cada uma das quatro cultivares apresentou umidade residual média muito próxima daquela pré-definida $(60 \%)$, durante o processo de secagem, as quais foram iguais a: $59,8 \%$ para a cv. Italiano; $59,5 \%$ para a cv. Débora Plus; 60,3\% para a cv. Santa Cruz; e $60,3 \%$ para a cv. Delícia (Tabela 2 , nota de rodapé). Assim, o rendimento que também é uma função da umidade residual do produto pronto, na pesquisa atual teve muito pouca influência de tal umidade residual.
$\mathrm{O}$ rendimento, em massa, das fatias frescas (Tabela 2) em produto pronto (tomate seco) foi maior para a cv. Delícia (14,4\%), a qual foi seguida da cv Débora Plus (13,5\%), da cv. Santa Cruz (13,3\%) e da cv. Italiano (12,7\%). Os sólidos totais (massa seca) das fatias frescas (Tabela 1) se constituíram no principal fator para explicar tais diferenças entre cultivares para seus rendimentos (Tabela 2): a cv. Delícia, por apresentar o maior valor de massa seca igual a $5,6 \%$ da massa total de fatia fresca, apresentou o maior rendimento (14,4\%); e, foi seguida da cv. Débora Plus (13,5\%) com 5,4\% de massa seca; da cv. Santa Cruz (13,3\%) com 5,2\% de massa seca; e da cv. Italiano $(12,7 \%)$, que apresentou o menor valor, $5,1 \%$, para a massa seca.

$\mathrm{O}$ rendimento em produto tomate seco determinado a partir do tomate inteiro fresco (matéria-prima) foi, como esperado, menor que àquele determinado a partir da fatia fresca de tomate, sendo que a cv. Débora Plus teve o maior rendimento de $9,1 \%$, e, foi seguida pelas cultivares Santa Cruz com 8,9\%, Delícia com 8,6\% e Italiano com 8,3\% (Tabela 2).

As perdas expressivas de matérias-primas, os tomates inteiros frescos, durante o preparo das fatias frescas, as quais foram quantificadas em 34,3\% para a cv. Italiano, 32,7\% para a cv. Débora Plus, 33,3\% para a cv. Santa Cruz e 39,8\% para a cv. Delícia (Tabela 2), explicam esses baixos rendimentos. $\mathrm{E}$, tais perdas determinadas para os tomates inteiros frescos (Tabela 2), juntamente com a concentração de sólidos totais expressos por massa seca (Tabela 1), explicam as diferenças de rendimento entre cultivares (Tabela 2). A cv. Delícia destacouse das demais, pois produziu a maior proporção de descarte $(39,8 \%)$, e isso muito contribuiu para baixar o rendimento do tomate inteiro fresco em produto pronto $(8,6 \%)$, mesmo apresentando em suas fatias frescas a maior porcentagem de sólidos totais $(5,6 \%)$, expressa por massa seca (Tabela 1 ).

Perdas expressivas de massa fresca, devido à retirada da porção locular do tomate inteiro juntamente com as sementes, geradas no processamento para a produção de tomate seco foram determinadas também em outras pesquisas. Para a cv. Carmem, Raupp et al. (2007) determinaram uma perda, média de três tratamentos, igual a $37,8 \%$, enquanto que Venske et al. (2004) determinaram 32,7\%. E, no processamento das cultivares Débora e Santa Cruz foram determinadas, por Fagundes et al. (2005), perdas de 39,7\% e 36,0\%, respectivamente.

Segundo Raupp et al. (2007), diferenças de resultados quanto à perda de matéria-prima para a mesma cultivar podem ser atribuídas aos operadores que removeram porçôes diferenciadas de porçôes não aproveitáveis (descartes), bem como à procedência da matéria-prima. Já, quando se trata de cultivares diferentes, além desses fatores, a massa seca (total 
Tabela 1 - Caracterização ${ }^{1}$ do tomate inteiro fresco e das fatias frescas de quatro cultivares, usando amostra de cinco unidades de tomates. Ponta Grossa, Paraná, 2007.

\begin{tabular}{|c|c|c|c|c|}
\hline \multirow[b]{2}{*}{ Parâmetros avaliados } & \multicolumn{4}{|c|}{ Cultivares de tomate } \\
\hline & Italiano & $\begin{array}{l}\text { Débora } \\
\text { Plus }\end{array}$ & Santa Cruz & Delícia \\
\hline \multicolumn{5}{|l|}{ Tomate inteiro } \\
\hline Massa por unidade, g & 119,2 & 155,0 & 162,5 & 207,1 \\
\hline $\begin{array}{l}\text { Volume por unidade, } \\
\mathrm{mL}\end{array}$ & 126,0 & 164,8 & 168,2 & 208,8 \\
\hline Massa específica & 0,946 & 0,940 & 0,966 & 0,992 \\
\hline \multicolumn{5}{|l|}{ Fatias frescas } \\
\hline Massa seca, \% & 5,1 & 5,4 & 5,2 & 5,6 \\
\hline Sólidos solúveis, ${ }^{\circ B}$ rix & 3,5 & 3,2 & 2,9 & 3,0 \\
\hline $\mathrm{pH}$ & 4,2 & 4,3 & 4,2 & 4,1 \\
\hline
\end{tabular}

${ }^{1}$ média de seis repetições (processamentos).

Tabela 2 - Balanço de massa do processamento e rendimento em produto tomate seco de quatro cultivares de tomate. Ponta Grossa, Paraná, 2007.

\begin{tabular}{|c|c|c|c|c|}
\hline \multirow[b]{2}{*}{ Parâmetros avaliados } & \multicolumn{4}{|c|}{ Cultivares de tomate $^{1}$} \\
\hline & Italiano & $\begin{array}{l}\text { Débora } \\
\text { Plus }\end{array}$ & $\begin{array}{l}\text { Santa } \\
\text { Cruz }\end{array}$ & Delícia \\
\hline Massa de tomate inteiro, $\mathrm{g}$ & $1.998,9$ & $2.018,1$ & $2.007,6$ & $2.009,4$ \\
\hline Massa de fatias frescas, $g$ & $1.313,2$ & $1.357,3$ & $1.339,4$ & $1.208,6$ \\
\hline Massa de fatias secas, $g$ & $166,7^{2}$ & $182,7^{3}$ & $177,9^{4}$ & $172,4^{5}$ \\
\hline $\begin{array}{l}\text { Perdas no preparo de } \\
\text { fatias frescas, } \%\end{array}$ & 34,3 & 32,7 & 33,3 & 39,8 \\
\hline $\begin{array}{l}\text { Rendimento de tomate } \\
\text { inteiro em tomate seco, \% }\end{array}$ & 8,3 & 9,1 & 8,9 & 8,6 \\
\hline $\begin{array}{l}\text { Rendimento de fatias } \\
\text { frescas em tomate } \\
\text { seco, \% }\end{array}$ & 12,7 & 13,5 & 13,3 & 14,4 \\
\hline
\end{tabular}

de sólidos), característica da cultivar, também explicam tais diferenças.

Produtos tomates secos são comercializados apresentando umidade residual, em geral, variando de no máximo cerca de $70 \%$ até um valor muito baixo de umidade, menos de $10 \%$. Para consumo como ingredientes de pratos a base de massa, como pizzas e lasanhas, bem como na forma de aperitivo, a secagem que se processa até níveis de umidade intermediários, que variam normalmente entre 45 e $70 \%$, deixa os produtos tomates secos prontos para tais usos.

Dados sobre o rendimento do tomate em produto tomate seco são importantes para a composição final do preço. $\mathrm{O}$ tomate inteiro fresco, por apresentar perdas expressivas durante o seu preparo em fatias frescas, bem como por apresentar uma proporção baixa de sólidos (massa seca), quando submetido à secagem resulta em produto tomate seco de baixo rendimento, o qual é, como esperado, também uma função da umidade residual de secagem. Portanto, teores mais altos de sólidos (massa seca) são desejados para a produção de tomate seco, pois contribuem para aumentar o rendimento em massa de produto pronto (Raupp et al., 2007).

As retiradas de porções de produto pronto (tomate seco) do secador durante o processamento de secagem foram semelhantes para as cultivares Italiano, Débora Plus e Santa Cruz (Figura 2). Já, para a cv. Delícia foram retiradas porçōes destacadamente bem menores de tomate seco a partir de seis horas de secagem.

Até quatro horas de secagem foram retiradas quantidades muito pequenas de produtos prontos para todas as cultivares (Figura 2), entre um máximo de 7,0\% (cv. Italiano) e um mínimo de 2,6\% (cv. Delícia). Duas horas depois (seis horas de secagem) ainda foi pouca a retirada da cr. Delícia $(15,7 \%)$, mas, para as demais cultivares as retiradas variaram de 32,1\% (cv. Santa Cruz) até 40,9\% (cv. Italiano). Decorridos sete horas e trinta minutos de secagem, a cv. Delícia apresentou uma retirada igual a $35,9 \%$, no entanto, as retiradas das demais cultivares representaram quase a totalidade de produto pronto, $90,0 \%$ para a cv. Italiano, 90,4\% para a cv. Débora Plus e $80,3 \%$ para a cv. Santa Cruz.

As cultivares, Italiano, Débora Plus, Santa Cruz e Delícia, apresentaram tempos médios de secagem de $8 \mathrm{~h}$ e $10 \mathrm{~min}, 8 \mathrm{~h}$ e $15 \mathrm{~min}, 8 \mathrm{~h}$ e $35 \mathrm{~min}$, e $9 \mathrm{~h}$ e $25 \mathrm{~min}$, respectivamente (Figura 2). Modificações na organização estrutural do tecido vegetal, as quais ocorrem durante o processo de secagem, devem ter influenciado na perda de umidade a partir das fatias de tomate, e, aparentemente explicam as diferenças entre tratamentos (cultivares de tomate) para os tempos de secagem.

$O$ processo de secagem deve ter produzido efeitos aparentemente distintos na transformação da estrutura física e química natural de fatias de tomate das diferentes cultivares, e, por conseguinte, no enrijecimento de seus produtos durante a secagem. Assim, para a cv. Delícia deve ter ocorrido durante a secagem, comparativamente, um enrijecimento mais intenso a partir da superfície de suas fatias. Os resultados da Figura 2 mostram que essa cultivar (Delícia) precisou de mais tempo para a retirada de iguais proporçôes de produtos prontos das demais cultivares, e, por isso, apresentou um maior tempo total de secagem.

A descrição para o aspecto visual com relação a coloração e o formato das fatias dos produtos tomates secos, bem como a avaliação sensorial feita por julgadores não treinados estão apresentados na Tabela 3. A cv. Italiano apresentou fatias secas com uma coloração vermelha mais escura, tipo bordô, bem como formato alongado e pequeno. Em contraste, as 
fatias da cv. Delícia apresentaram uma predominância de cor alaranjada com pouca cor vermelha clara, de tamanho grande e arredondadas. A cv. Débora Plus e a cv. Santa Cruz apresentaram cor vermelha clara, e os tamanhos foram intermédios entre a cv. Italiano e cv. Delícia.

Os produtos tomates secos das quatro cultivares (Italiano, Débora Plus, Santa Cruz, Delícia) não apresentaram diferença significativa quanto ao paladar (Tabela 3) quando foram degustados por provadores não treinados (média de 180). Os tomates secos receberam as seguintes pontuaçôes dos provadores: cv. Italiano 5,97, cv Débora Plus 6,35, cv. Santa Cruz 6,02 e cv. Delícia 5,84.

Em comentários feitos voluntariamente por alguns julgadores, o tamanho grande e arredondado bem como a presença de coloração amarela nas fatias da cv. Delícia (Tabela 3), foram características que depreciaram a aparência de seu produto tomate seco. Em contraste, os tomates secos produzidos a partir da cv. Italiano e da cv. Débora Plus receberam alguns comentários de satisfação por parte de julgadores quanto à cor, que foi tipicamente vermelha escura tipo bordô, e ao gosto. $\mathrm{O}$ formato alongado das fatias da cv.

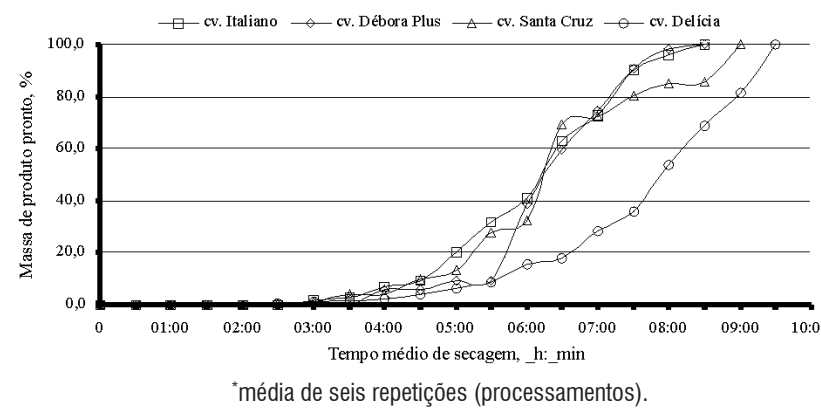

Figura 2 - Distribuição da retirada do secador de produto pronto (valor acumulado, em \%) de quatro cultivares por intervalo de secagem. Ponta Grossa, Paraná, 2007.

Tabela 3 - Aspecto visual comparativo das fatias de produtos tomates secos e resultado da avaliação sensorial quanto ao gosto, para quatro cultivares de tomate. Ponta Grossa, Paraná, 2007.

\begin{tabular}{lllll}
\hline Característica & $\begin{array}{l}\text { Cultivares } \\
\text { Italiano }\end{array}$ & $\begin{array}{l}\text { Débora } \\
\text { Plus }\end{array}$ & Santa Cruz & Delícia \\
\hline Coloração & $\begin{array}{l}\text { Vermelho } \\
\text { escuro, } \\
\text { tipo bordô }\end{array}$ & $\begin{array}{l}\text { Vermelho } \\
\text { claro }\end{array}$ & $\begin{array}{l}\text { Vermelho } \\
\text { claro }\end{array}$ & $\begin{array}{l}\text { Predominância } \\
\text { de alaranjado, } \\
\text { pouco vermelho } \\
\text { claro }\end{array}$ \\
Formato ${ }^{1}$ & $\begin{array}{l}\text { Tamanho } \\
\text { pequeno e e } \\
\text { alongado }\end{array}$ & $\begin{array}{l}\text { Tamanho } \\
\text { intermédio }\end{array}$ & $\begin{array}{l}\text { Tamanho } \\
\text { intermédio }\end{array}$ & $\begin{array}{l}\text { Tamanho grande } \\
\text { e arredondado }\end{array}$ \\
Gosto $^{2}$ & 5,97 A & 6,35 A & 6,02 A & 5,84 A \\
\hline
\end{tabular}

${ }^{1}$ em cinco repetições; ${ }^{2}$ avaliação sensorial, valores médios de 180 repetições (julgadores).
Italiano, que conferiu um aspecto agradável, também chamou a atenção de alguns julgadores.

Também, alguns julgadores manifestaram, voluntariamente, os seguintes comentários: a característica de doçura das fatias foi facilmente percebida nos tomates secos das cultivares Italiano e Débora Plus e menos na cv. Santa Cruz, sendo que o produto da cv. Delícia apresentou apenas traços de doçura. $\mathrm{E}$, com relação à mastigação (textura ao dente), as fatias secas de tomate da cv. Delícia apresentaram alguma resistência e precisaram de mais tempo de mastigação.

\section{CONCLUSÕES}

A cv. Delícia apresentou a maior perda (descarte de $39,8 \%$ ) durante o preparo de fatias frescas de tomate, e, as perdas de matéria-prima (tomate inteiro fresco) para as cultivares Italiano, Débora Plus e Santa Cruz variaram de 32,7 a $34,3 \%$.

Os rendimentos, em massa, dos tomates inteiros em produtos "tomate seco" foram de 9,1\% para a cv. Débora Plus, 8,9\% para a cv. Santa Cruz, 8,6\% para a cv. Delícia e $8,3 \%$ para a cv. Italiano.

O produto tomate seco da cv. Delícia precisou de mais tempo para ficar pronto ( 9 horas e 25 minutos), e, as cultivares Italiano e Débora Plus apresentaram baixos tempos de secagem, 8 horas e 10 minutos e 8 horas e 15 minutos, respectivamente.

Os produtos tomates secos produzidos a partir das cultivares Italiano, Débora Plus, Santa Cruz e Delícia não apresentaram diferenças significativas quanto ao gosto, quando degustados por julgadores não treinados (total de 180).

\section{BIBLIOGRAFIA CITADA}

Alves, S.M.; Silveira, A.M. 2002. Estudo da secagem de tomates desidratados e não desidratados osmoticamente. Revista Universidade Rural, Série Ci. Exatas Terra, Universidade Federal Rural do Rio de Janeiro, 21(1): 21-30.

Anzaldúa-Morales, A. 1994. La evaluación sensorial de los alimentos en la teoría y la práctica. Editora Acribia, Zaragoza, España. 198p.

Camargo Filho, W.P.; Mazzei, A.R. 1996. Necessidade de reconversão da produção de tomate em São Paulo: ações na cadeia produtiva. Informaçôes Econômicas, São Paulo, 26: 105-116.

Fagundes, A.F.; Onuki, N.S.; Raupp, D.S.; Gardingo, J.R.; Borsato, A.V. 2005. Influência do grau de umidade na textura de tomate seco refrigerado ou envasado em óleo. Publicatio UEPG Ci. Exatas Terra, Ci. Agr. Eng., Ponta Grossa, 11(1): 35-42.

Fellows, P. 1994. Tecnología del processado de los alimentos: principiosy prácticas. Traducido por: Trepat, F.J.S.. Editora Acribia, Zaragoza, España. p.1,21,287-293. 
Fett, C. 2000. Ciência da suplementação alimentar. Editora Sprint, Rio de Janeiro. p.54-57, 71-75.

Giovanucci, E.; Ascherio, A.; Rimm, E.B.; Stampfer, M.J.; Colditz, G.A.; Willett, W.C. 1995. Increase of carotenoids and retinal in relation to risk of prostate cancer. Journal of National Cancer institute, Oxford-UK, 87: 1767-1776.

Raupp, D.S.; Gabriel, L.S.; Vezzaro, A.F.; Daros, P.Á.; Chrestani, F.; Gardingo, J.R.; Borsato, A.V. 2007. Tomate longa vida desidratado em diferentes temperaturas de secagem. Acta Scientiarum. Agronomy, Maringá, 29(1): 33-39.
Romero-Peña, L.M.; Kieckbusch, T.G. 2003. Influência de condições de secagem na qualidade de fatias de tomate. Brazilian Journal of Food Technology, Campinas, 6: 69-76.

Sgarbieri, V.C.; Pacheco, M.T.B. 1999. Revisão: Alimentos funcionais fisiológicos. Brazilian Journal of Food Technology, Campinas, 2(1,2): 7-19.

Silva, J.B.C.; Giordano, L.B. 2000. Tomate para processamento industrial. Embrapa Comunicação para transferência de tecnologia, Embrapa Hortaliças, Brasília. 168p.

Tolonen, M. 1995. Vitaminas y minerales en la salud y la nutrición. Editora Acribia, Zaragoza, España. p.133-140,150-155.

Venske, C.; Santos, J.; Raupp, D.S.; Gardingo, J.R.; Borsato, A.V. 2004. Influência do grau de maturação nas características sensoriais de tomate seco envasado em óleo. Publicatio UEPG Ci. Exatas Terra, Ci. Agr. Eng., Ponta Grossa, 10(3): 33-40.

Recebido em 28/11/2007

Aceito em 11/03/2009 
